\title{
An adaptive algorithm for performance assessment of construction project management with respect to resilience engineering and job security
}

\author{
P. Hashemi, R. Yazdanparast*, A. Ghavamifar and A. Azadeh
}

School of Industrial Engineering, College of Engineering, University of Tehran, Tehran, Iran

\section{H R O N I C L E \\ A B S T R A C T}

Article history:

Received: July 5, 2017

Received in revised format: Octo-

Construction sites are accident-prone locations and therefore safety management plays an important role in these workplaces. This study presents an adaptive algorithm for performance assessment of project management with respect to resilience engineering and job security in a ber 10,2017

Accepted: October 10, 2017

Available online:

October 12, 2017

Keywords:

Resilience engineering

Construction project management

Performance assessment

Artificial neural networks

Job security large construction site. The required data are collected using questionnaires in a large construction site. The presented algorithm is composed of radial basis function (RBF), artificial neural networks multi-layer perceptron (ANN-MLP), and statistical tests. The results indicate that preparedness, fault-tolerance, and flexibility are the most effective factors on overall efficiency. Moreover, job security and resilience engineering have similar statistical impacts on overall system efficiency. The results are verified and validated by the proposed algorithm.

2018 Growing Science

\section{Introduction}

Construction sites are accident-prone locations and therefore safety management plays an important role in these workplaces (Sacks et al., 2009). Resilience engineering (RE) is a factor that makes senses in a construction site as a high-risk organization (Wehbe et al., 2016). Resilience engineering enhances preventive safety, leads to a more reliable system performance in emergency state and increases the system flexibility when accidents occur. Also, job security has a psychological effects on employees' performance and enhances their efficiency (Reisel et al., 2010).

\subsection{Resilience engineering}

Resilience Engineering (RE) is a main key in safety management and has a firm relation with human factors. In the literature it has been defined as the ability of a system to keep or restore quickly to its normal function when an unexpected change or failure occurs (Woods \& Hollnagel, 2006). Resilience engineering can impede the sudden incidents and mishaps (Dinh et al., 2012), while safety is defined

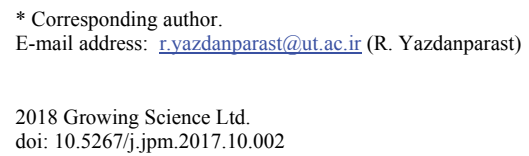


in RE literature as the ability of industries to deal with disruptions and fluctuations. Although the attention of RE to normal condition work environment, it emphasizes more on learning from accidents and unexpected disruptions (Saurin \& Junior, 2012). In a resilient system, six indexes are introduced that have special meaning in different types of organizations. These identifying areas are listed below (Wreathall, 2006):

- Top management commitment (TMC): Refers to a factor of RE that consider the management's emphasis on recognition of the disruptions and the effort to solve them (Wreathall, 2006). The importance of good performance is determined as a commitment in the organizations that management is responsible to make it.

- Reporting culture (RC): It demonstrates a rate of the report that workers share with managers about the problems and failures in the organization. RC helps to recognize the cause of problems and to enhance resilience of the systems (Wreathall, 2006).

- Learning: RE considers learning on two aspects of normal work and disturbance condition in an organization (Wreathall, 2006).

- Awareness: By data collection, management identifies the quality of performance and also workers will be conscious of the current status in the overall system (Rasmussen, Pejtersen, \& Goodstein, 1994). Awareness can help to assess and evaluate the future failures would be occurred in the organization.

- Preparedness: It identifies as the ability of organizations to predict the problems and make preparation to deal with them (Wreathall, 2006).

Flexibility: A flexible system can adapt to unexpected events or new problems and helps the organization to solve problems without making the overall system dysfunction (Rasmussen et al., 1994).

\subsection{Integrated resilience engineering}

In addition to the factors listed above, four indexes are introduced for complex systems and hazardous incidents (Azadeh et al., 2017a). These indexes are as follows:

- Self-organization: It focuses on decentralized decision-making so that any units can plan and operate independently and when an accident occurred the authority is given to any units to decide without going through the orders of a hierarchical decisions (Plowman et al., 2007).

- Teamwork: This item implies the capability of the system for working as a team and sections are aware of each other's with mutual support which causes decreasing in the workload (Burtscher \& Manser, 2012).

- Redundancy: It is the foresight of the system to consider extra resources and alternatives to encounter emergency states when some facilities or human resources are unavailable (Frangopol \& Curley, 1987).

Fault-tolerant: It means if some components or operators of system confront a disorder, system can operate continuously in a proper manner (Domínguez-García et al., 2008).

\subsection{Job security}

Job security is one of the most important factors in human resource management (HRM) which depends on personnel capacity, employment status, economic situations and etc. When a person can keep his or her job in future, he/she has job security and there is a low risk of becoming unemployed (Azadeh et al., 2014). Job security is taken for psychological situations that workers treated differently against the possibility of continuing their work with an organization (Loi et al., 2011). 


\subsection{Construction project management}

There are many problems in management of construction projects due to complexity in their environments. Therefore, much attention has been paid to it for achieving the efficiency in cost, time, safety, and quality (Fewings, 2013). Design, Planning, coordinating, and balancing schedule, time, cost, domain, and maintenance are the stages of construction project management (Siang \& Yih, 2012).

Human resource management is an important factor in project management (PM). Individual skills, teamwork, and leadership are significant properties for project management (Fewings, 2013), so it is essential to focus on assessment and evaluation of personnel's performance and efficiency. Also, safety management plays an important role in construction project management. The activities such as prevention of accidents and implementation of safety management can help to reduce accidents that are an integral part of the construction project (Fewings, 2013).

This study presented an adaptive algorithm for evaluation of the efficiency for each decision making unit (DMU) in project management field. In this paper the efficiency has been evaluated based on RE factors and job security for each DMU that are taken for operators of project. The research has been done by questionnaire design and then, data collection from the questionnaire has been distributed among the project managers in a large construction site in Iran. To predict the effect of RE and job security on the efficiency of DMUs from collected data, ANN algorithm has been utilized and then by doing the sensitivity analysis, the effects of each factor on the efficiency scores of operators have been illustrated.

\section{Literature review}

\subsection{Job security}

The workforce has a significant role in the assessment of the efficiency in project management and human resource management field. Recent studies have been focused on identifying factors affecting on the performance of operators in different industries with respect to work motivational factors (WMF) like job security. Azadeh and Ahranjani (2014) analyzed the impact of human factors such as job security, job satisfaction and job stress on the evaluation of the performance through data envelopment analysis (DEA). The assessment of workplace clarified that workers' concerns about their job security impacted on their health behaviors (Turner \& Lingard, 2016). Azadeh et al. (2014) presented an adaptive algorithm to evaluate workers' performance based on two factors which are job security and HSEE. They considered HSEE as an input and job security as an output of the algorithm; job security was measured due to HSEE and then used for analyzing the performance of operators. Blader and Tyler (2009) focused on workers' conception of job security which is a significant item in preservation of a positive social personality. They claimed that job security makes the employee interested in the development of the organization and will be effect on their opinion about the obligation on organization profitability. Ma et al. (2016) studied the individual differences on the relevance of organizational identification, job security, and work performance. They mentioned that while workers are concern about their employment, they can't do their duties well because of stressful state; based on previous studies the positive relation has been explored between these two factors by (Cheng \& Chan, 2008; Reisel et al., 2010; Staufenbiel \& König, 2010).

\subsection{Resilience engineering}

To the best of our knowledge few studies discussed RE concepts in the construction project. In one study, Wehbe et al. (2016) distinguished the relation between resilience and construction safety management for performance and risk assessment by using social network analysis (SNA) in safety networks. While only resilience was analyzed in this study and there is no discussion about RE and its factors. 
Recent researchers studied and analyzed RE factors in different fields. RE concepts are discussed in literature. An study on recognizing the challenges and constraints in the method of building resilience engineering and its adaptive ability has been performed by (Shirali et al., 2012). They categorized RE factors in nine classes in a chemical plant.

Several studies focused on assessment of safety management with respect to RE. Saurin and Júnior (2011) presented an improvement of an approach for evaluation of health and safety management systems (HSMS) in an electricity distributor. Costella, Saurin, and de Macedo Guimarães (2009) introduced an approach to assess health and safety management systems from RE viewpoint with considering three main aspects of health and safety (HS) and effect of four indexes of RE on HS.

The impact of RE factors on Human resource management (HRM) and performance assessment is one of the areas that have been considered in recent studies. Azadeh and Zarrin (2016) proposed an algorithm for evaluation of performance and analysis of HRM with respect to three concepts including RE, HSEE, and WMF that implemented in a petrochemical plant. In a recent studies, Azadeh et al. (2017b) presented an intelligent algorithm for performance evaluation of IRE and lean production principles in a pipe manufactory. In different case studies, RE is implemented in sea fishing and the relationship between RE and safety management was investigated and efforts made to decrease the accidents et al., 2009). Azadeh et al. (2015) used RE for improvement job satisfaction in hazardous labs. Ray-Sannerud, Leyshon, and Vallevik (2015) provided a framework for healthcare workers' performance as an index for proactive safety management systems by RE.

In this study, for the first time, ten factors of integrated RE beside one of the work motivational factors, namely job security are used to assess project management in a construction site. A comparison of significant features of this study and recent researches in this scope is summarized in Table 1.

\section{Table 1}

The comparison of this study with similar studies in this area

\begin{tabular}{|c|c|c|c|c|c|c|}
\hline \multirow[b]{2}{*}{ Studies } & \multicolumn{6}{|c|}{ Features } \\
\hline & WMF & $\mathrm{RE}$ & $\begin{array}{l}\text { efficiency } \\
\text { evaluation }\end{array}$ & $\begin{array}{c}\text { Assessment of } \\
\text { PM }\end{array}$ & $\begin{array}{c}\text { Construction } \\
\text { project }\end{array}$ & $\begin{array}{l}\text { Intelligent adap- } \\
\text { tive algorithm }\end{array}$ \\
\hline Azadeh et al. (2014) & $\checkmark$ & & $\checkmark$ & & & $\checkmark$ \\
\hline Azadeh and Zarrin (2016) & $\checkmark$ & $\checkmark$ & $\checkmark$ & & & $\checkmark$ \\
\hline $\begin{array}{l}\text { Azadeh and Ahranjani } \\
\text { (2014) }\end{array}$ & $\checkmark$ & & $\checkmark$ & & & \\
\hline Ma et al. (2016) & $\checkmark$ & & $\checkmark$ & & & \\
\hline Azadeh et al. (2015) & $\checkmark$ & $\checkmark$ & $\checkmark$ & & & $\checkmark$ \\
\hline This study & $\checkmark$ & $\checkmark$ & $\checkmark$ & $\checkmark$ & $\checkmark$ & $\checkmark$ \\
\hline
\end{tabular}

\section{Methodology}

In this study for assessment and measurement of the efficiency among project managers with respect to RE factors and job security, an adaptive intelligent algorithm (an ANN-RBF algorithm) was presented. To demonstrate the effectiveness and preference of the algorithm, a large construction site is selected as a case study. By questionnaire design and data collection, obtained data for ten factors of RE was defined as inputs. Outputs of the algorithm are collected data for job security factor. Then the adaptation of actual outputs and ANN output was checked by this algorithm and the efficiency of DMUs was calculated. ANN is a skilled algorithm to explore uncertainty and noise. Eleven steps which are explained in the following should be run to attain the objective of this algorithm. Fig. 1 shows the flowchart of the intelligent algorithm for evaluation of project management with respect to job security and RE. 


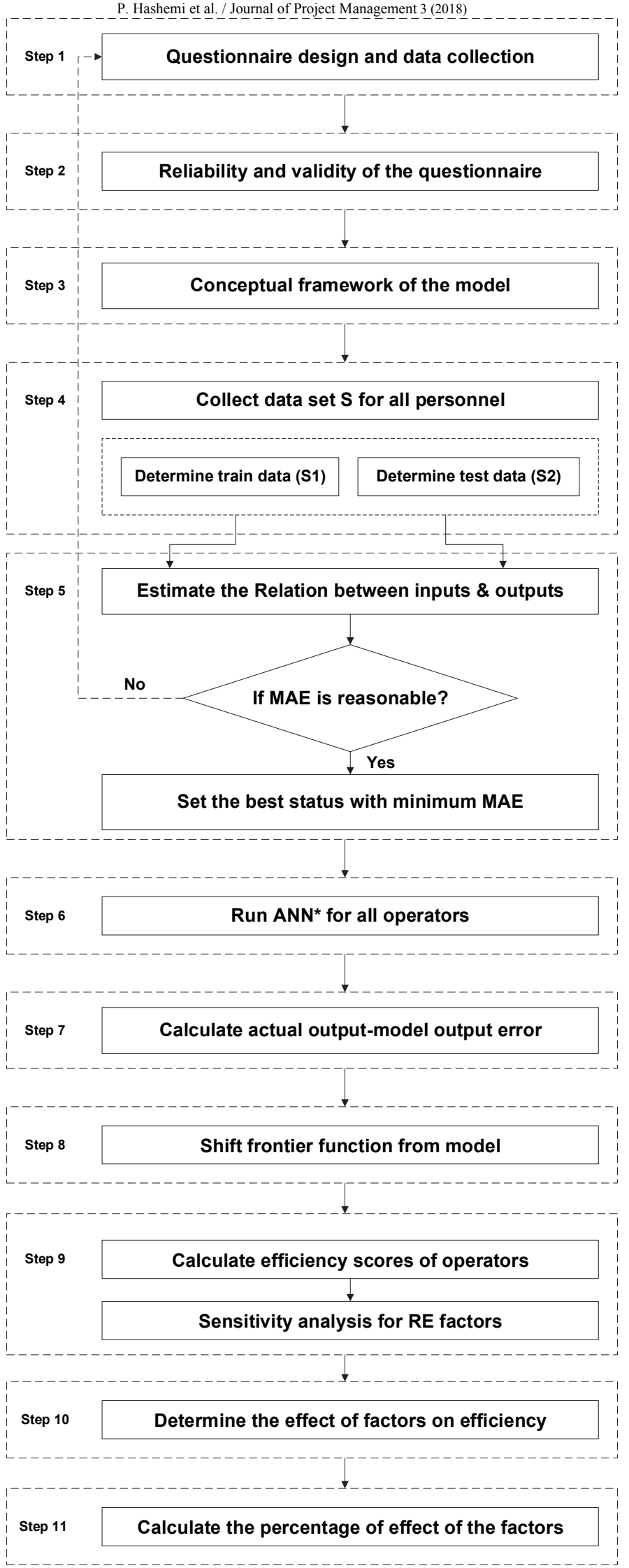

Fig. 1: The flowchart of intelligent algorithm with respect to job security and RE 
The questionnaire contains 22 questions about RE factors and job security ( 2 questions for each factor) and for each question, a continuous score among 1 to 20 has been considered. Also in the questionnaire has not asked the name of personnel and only general information like as gender, age, education and work experience are gathered. Then these questionnaires are distributed among the project managers in different departments of a construction site. The samples of questions for each factor are presented in Appendix 1.

Step 2. Reliability and validity test of questionnaire

The capability to produce the same results in different cases is called reliability of the questions. For evaluating the reliability of the questionnaire, Cronbach's Alpha should be calculated for all questions. Since the questionnaire has been confirmed by experts, there is no need to do the validity test by factor analysis.

\section{Step 3. Conceptual framework of the model}

In this step the input and output variables of the model are determined.

Step 4. Collect data set $S$ for all personnel

It explains that the relationship between inputs and outputs for operators that in this study are considered as DMUs should be assessed. Then $\mathrm{S}$ is divided into 2 subsets: train data (S1) and test data (S2).

Step 5. Use the algorithm to estimate the inputs-outputs relationship

- For ANN choose architecture and training parameters.

- Use train data (S1) for training the model.

- Use test data (S2) for evaluation of the model.

- Repeat above steps by using new architecture and training data for ANN.

- For the learned algorithm, the relative error $\left(\mathrm{MAE}^{1}\right)$ must be determined.

If MAE $\leq 0.20$, then go to the next step; otherwise it shows that there aren't major variations among operators according to skills, experience, and education and therefore distribution of questionnaire among more operators is needed.

- With respect to minimum MAE on the test data sets, adjust the best structure of the network $(\mathrm{ANN} *)$.

Step 6. Run $A N N^{*}$ for all operators.

Step 7. Compute the errors that exists between the actual output $\left(P_{\text {real }(i)}\right)$ and output obtained by ANN $\left(P_{A N N^{*}(i)}\right)$ for assessment of all operators:

$$
\mathrm{E}_{\mathrm{i}}=\mathrm{P}_{\text {real }(\mathrm{i})}-\mathrm{P}_{\mathrm{ANN} *(\mathrm{i})} \quad(\mathrm{i}=1, \ldots, \mathrm{n})
$$

Step 8. Shift frontier function from model

${ }^{1}$ Mean Absolute Error, MAE $=\frac{1}{N} \sum_{i=1}^{N}\left|\frac{\text { Actual value }_{i}-\text { Setpoint value }_{i}}{\text { Setpoint value }_{i}}\right|$, (N: the number of rows) 
It is done to determine the effect of one of the unique attribute of the algorithm that is called the largest positive error:

$$
\mathrm{E}_{\mathrm{i}}^{\prime}=\mathrm{E}_{\mathrm{i}} / \mathrm{P}_{\mathrm{ANN} *(\mathrm{i})} \quad(\mathrm{i}=1, \ldots, \mathrm{n})
$$

This formula computes the largest error due to the operator scale (Constant Returns to Scale (CRS)). The largest $E_{i}^{\prime}$ that demonstrates the best operator in performance, is recognized for achieving this end. The kth operator is considered as the largest $E_{i}^{\prime}$ and therefore

$$
\mathrm{E}_{\mathrm{k}}^{\prime}=\max \left(\mathrm{E}_{\mathrm{i}}^{\prime}\right)
$$

The shift value is calculated by the following formula and it is different for each operator:

$$
\mathrm{Sh}_{\mathrm{i}}=\mathrm{E}_{\mathrm{k}} \times \frac{\mathrm{P}_{\mathrm{ANN} *(\mathrm{i})}}{\mathrm{P}_{\mathrm{ANN} *(\mathrm{k})}} \quad(\mathrm{i}=1, \ldots, \mathrm{n})
$$

In this method the scale effect of the operators on efficiencies is considered. Also, the selected unit for correction is chosen according to its scale (CRS).

Step 9. Calculate total efficiency scores due to job security and RE

The efficiency scores can take a value between 0 and 1 . The selected unit for correction is where the maximum score is assigned to it (Azadeh et al., 2017b).

$$
\mathrm{F}_{\mathrm{i}}=\mathrm{P}_{\mathrm{i}} /\left(\mathrm{P}_{\mathrm{ANN} *(\mathrm{i})}+\mathrm{Sh}_{\mathrm{i}}\right) \quad(\mathrm{i}=1, \ldots, \mathrm{n})
$$

Step 10. Perform sensitivity analysis for factors to determine the effect of each factor on efficiency scores by $A N N$.

For identification of the effect of factors, this step should be implemented. It is done by deleting each factor and run ANN without this factor.

Step 11. Calculate the percentage of the effect of each factor on efficiency.

\section{Experiments}

A large construction site in Tehran, Iran is selected as a case study for implementation of the proposed approach. The entire project consists of the commercial sector, bridge and road, two office towers, parking, two hotels, and banquet hall. The project was started in 2011 with about 7000 human resources which is one of the largest construction projects in terms of extent in Iran. The construction site is a high-risk workplace with much noise and uncertainties. It seems that RE can play a key role for assessment of project management in this place. Also, because of the project-based structure of construction site, job security is taken for as an important factor. The questionnaires were distributed in bridge and road construction site among 50 operators in some sectors such as the executive section, QC management, construction surveying, project control and administrative unit and then we asked them to answer the questions and grade them based on continuous whole number 1 through 20. Finally, 35 questionnaires were returned that the details of the respondents' information are reported in Fig. 2. 
Among the questionnaire respondents, about $83 \%$ are male and $25-40$ years old. They have included all level of work experiences almost similar to each other's. The majority of them have B.s degree educational level. The work time in this workplace is more than usual and $88 \%$ of operators have worked more than 8 hours in a day.

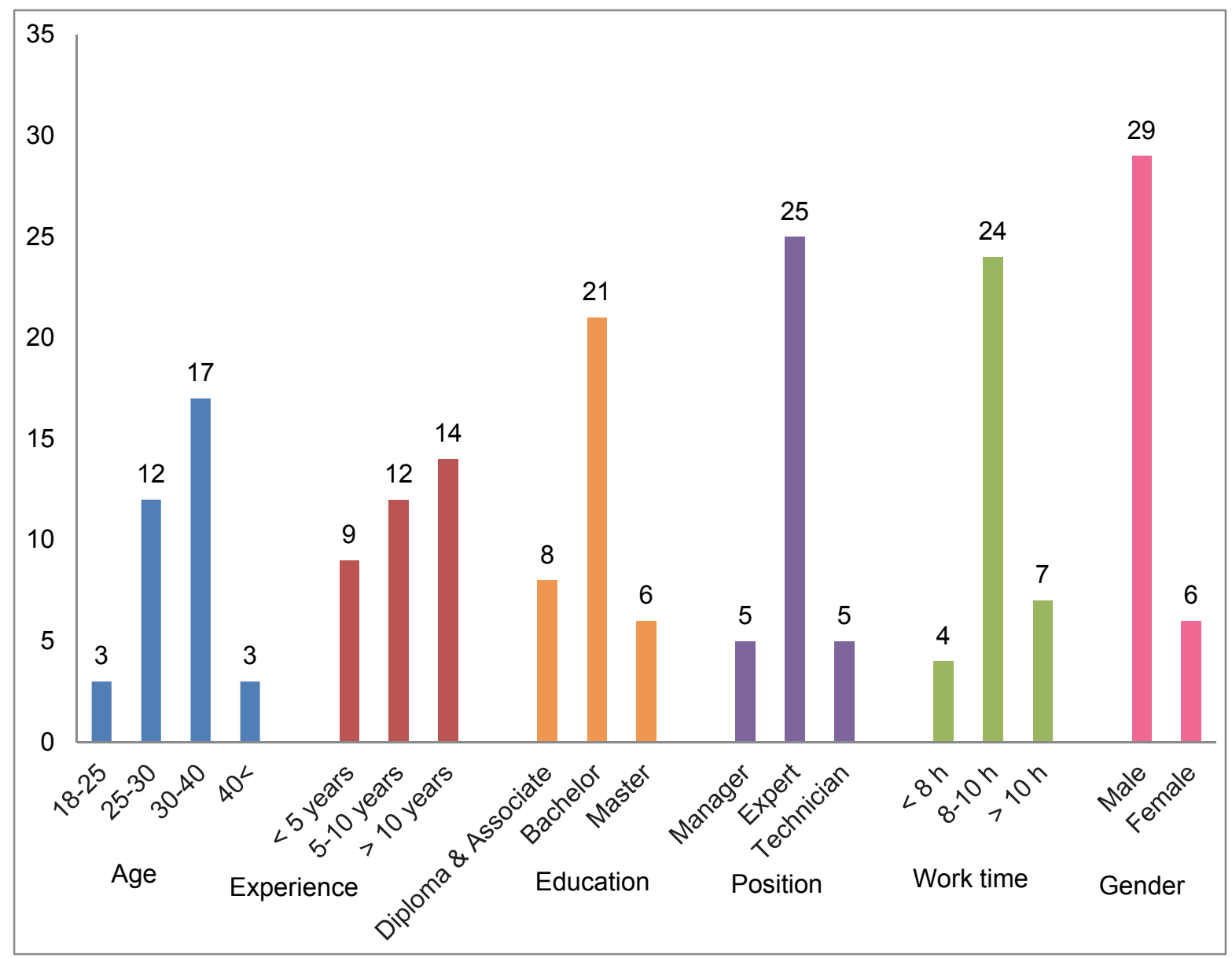

Fig. 2. The demographic details of correspondents

\subsection{Reliability test and T-test}

To test the reliability of the questionnaire, calculation of Cronbach's alpha for each factor that including 10 factors of RE and job security as well as total data are required. If the calculated value for $\alpha$ is greater than or equal to 0.7 , the reliability of questions will be accepted (Cronbach, 1951). In this study the value of $\alpha$ for all factors was greater than 0.7 and none of them were removed. In Table 2, the Cronbach's alpha of each factor is presented.

For comparing the means, independent two sample t-test have been used in Minitab for each factor and the p-values of all factors have been obtained greater than $\alpha=0.05$, indicates that there is no reason to reject $\mathrm{H}_{0}$. The result of the test is given in Table 2 . 
Table 2

Reliability and validity results

\begin{tabular}{cccc}
\hline Concept & Factor & Cronbach's alpha & p-value of T-test \\
\hline \multirow{4}{*}{ IRE } & Management commitment & 0.851 & 0.607 \\
& Report culture & 0.905 & 0.738 \\
& Learning & 0.736 & 0.204 \\
& Awareness & 0.749 & 0.139 \\
& Preparedness & 0.721 & 0.907 \\
& Flexibility & 0.717 & 0.945 \\
& Self-organization & 0.913 & 0.932 \\
& Teamwork & 0.728 & 0.473 \\
\hline WMF & Fault-tolerance & 0.764 & 0.268 \\
\hline & Redundancy & 0.827 & 0.778 \\
\hline
\end{tabular}

The minimum, maximum and mean of collected data were calculated for each factor and reported in Table 3 .

Table 3

Minimum, Mean and Maximum of data for each factor

\begin{tabular}{cccc}
\hline Factor & Min & Mean & Max \\
\hline Management commitment & 0.35 & 13.26 & 20 \\
Report culture & 5 & 14.9586 & 20 \\
Learning & 5 & 12.3229 & 20 \\
Awareness & 5.2 & 13.7829 & 20 \\
Preparedness & 9.05 & 15.4643 & 20 \\
Flexibility & 2.5 & 11.9486 & 18.5 \\
Self-organization & 0.1 & 11.0975 & 19.9 \\
Teamwork & 5 & 13.2271 & 19.5 \\
Fault-tolerance & 5 & 13.6429 & 18.45 \\
Redundancy & 5 & 15.5629 & 20 \\
Job security & 0.1 & 11.88 & 19.75 \\
\hline
\end{tabular}

\section{Results and analysis}

For assessment of project management with respect to job security and RE factors, an adaptive neural network algorithm is developed. In the following the main steps of algorithm are mentioned.

Step 1. At first, the average of data set for each factor that are given in Appendix 2 was determined as the output and input variables. Job security was considered as an output and RE factors were the inputs of the algorithm.

Step 2. Then the best structure of the ANN-RBF algorithm was chosen by changing the spread and maximum number of neurons. The lowest MAE was obtained from the minimum average of five runs for each structure. The results are shown in Table 4. 
Table 4

Different architectures of ANN-RBF model

\begin{tabular}{ccccccccc}
\hline \multirow{2}{*}{ Number } & Spread & $\begin{array}{c}\text { Maximum } \\
\text { number of } \\
\text { neurons }\end{array}$ & Run 1 & Run 2 & Run 3 & Run4 & Run5 & Average \\
\cline { 6 - 9 } & & 10 & 0.0863 & 0.0816 & 0.0831 & 0.0796 & 0.0719 & 0.08050 \\
\hline 1 & 3 & 15 & 0.0775 & 0.0855 & 0.0737 & 0.0949 & 0.0867 & 0.08366 \\
2 & 4 & 25 & 0.1396 & 0.1748 & 0.1270 & 0.1358 & 0.0845 & 0.13234 \\
3 & 0.7 & $\mathbf{1 5}$ & $\mathbf{0 . 0 3 8 5}$ & $\mathbf{0 . 0 4 0 1}$ & $\mathbf{0 . 0 4 3 2}$ & $\mathbf{0 . 0 4 0 2}$ & $\mathbf{0 . 0 4 8 9}$ & $\mathbf{0 . 0 4 2 1 8}$ \\
$\mathbf{4}$ & $\mathbf{2}$ & 12 & 0.0763 & 0.0807 & 0.0698 & 0.0700 & 0.0825 & 0.07586 \\
5 & 4 & 10 & 0.0556 & 0.0473 & 0.0680 & 0.0571 & 0.0645 & 0.05850 \\
6 & 3 & 15 & 0.1048 & 0.1121 & 0.0984 & 0.0982 & 0.0894 & 0.10058 \\
7 & 6 & 20 & 0.0799 & 0.0617 & 0.0747 & 0.0669 & 0.0658 & 0.06980 \\
\hline 8 & 4 & & & & & & & \\
\hline
\end{tabular}

Step 3. The optimum structure was set for the algorithm for assessment project management with respect to job security and RE. Then run ANN-RBF and output of ANN was obtained for each DMU. According to the algorithm, the total efficiency scores of DMUs were calculated. The obtained efficiency scores are presented in Table 6 .

Step 4. Sensitivity analysis was performed on efficiency scores of each factor. This step was done by emitting individual factors and running algorithm without these factors to determine the effect of each factor on total efficiency. The results of this step are given in Table 6.

Step 5: The impact of each factor on total efficiency was checked by t-test in Minitab. Paired t-test is applied between obtained efficiency scores before and after elimination of each factor. If the p-value is lower than 0.05 , the hypothesis will be accepted and shows that elimination of the factor has no significant effect on total efficiency. The positive or negative impact of factors is determined by comparison of the average of total efficiency scores before and after elimination for each factor. The result of $t$-test is presented in Table 5 .

\section{Table 5}

T-test results and effect of factors on efficiency scores

\begin{tabular}{cccc}
\hline Factor & P-value of T-test & Result of test & Effect \\
\hline TMC & 0.503 & Acceptance of $\mathrm{H}_{0}$ & NSNE \\
Report culture & 0.387 & Acceptance of $\mathrm{H}_{0}$ & NSNE \\
Learning & 0.835 & Acceptance of $\mathrm{H}_{0}$ & Positive effect \\
Awareness & 0.036 & rejection of $\mathrm{H}_{0}$ & Positive effect \\
Preparedness & 0.000 & rejection of $\mathrm{H}_{0}$ & Positive effect \\
Flexibility & 0.001 & rejection of $\mathrm{H}_{0}$ & NSNE \\
Self-organization & 0.564 & Acceptance of $\mathrm{H}_{0}$ & NSNE \\
Teamwork & 0.349 & Acceptance of $\mathrm{H}_{0}$ & Positive effect \\
Fault-tolerance & 0.001 & rejection of $\mathrm{H}_{0}$ & NSNE \\
Redundancy & 0.129 & Acceptance of $\mathrm{H}_{0}$ & Positive effect \\
Job security & 0.000 & rejection of $\mathrm{H}_{0}$ &
\end{tabular}

Note: NSNE =Non-significant negative effect

Based on the results shown in Table 5, among 11 factors that are considered in integrated model, Awareness has a significant positive effect on total efficiency score. 


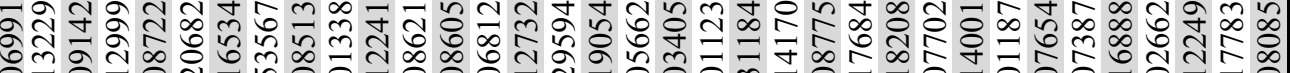

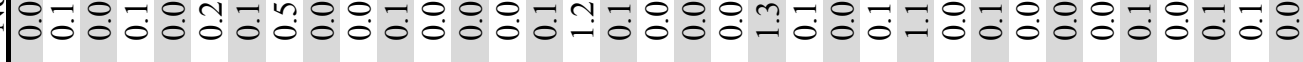

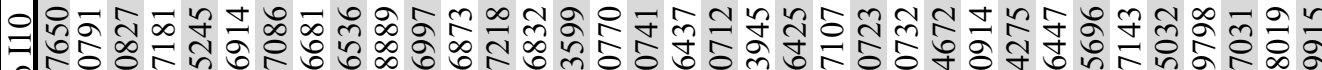

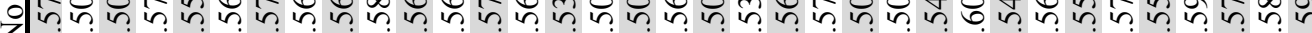
00000000000000000000000000000000000

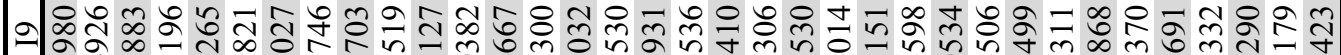
ұ

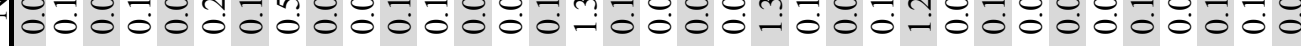

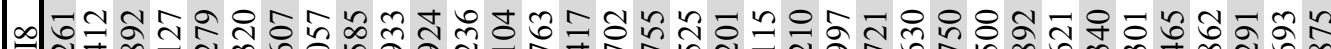

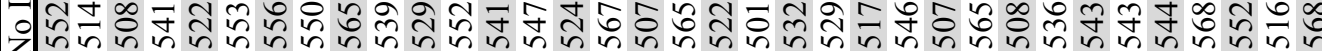
00000000000000000000000000000000000

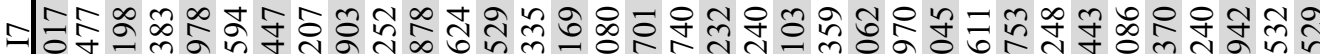

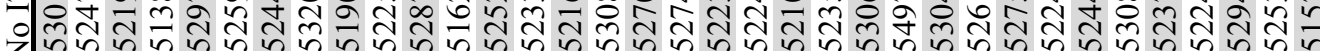
00000000000000000000000000000000000

의운

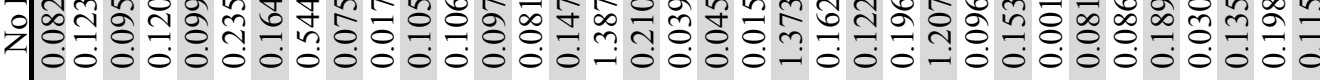
:

에은

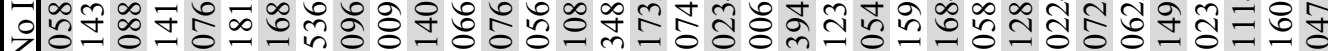

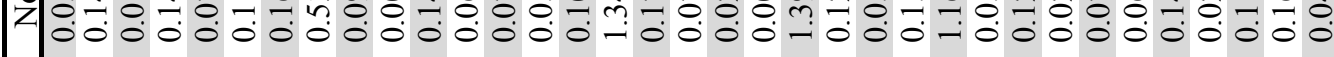

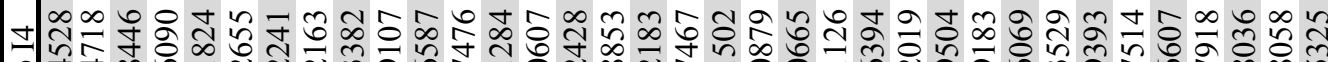

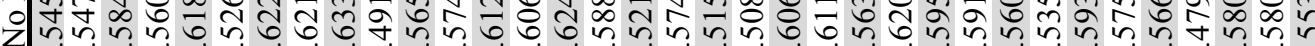
$000000000000000000000000000000-0000$

mำษ

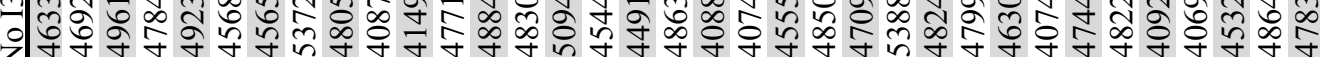

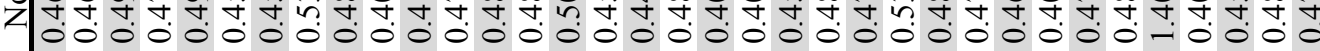

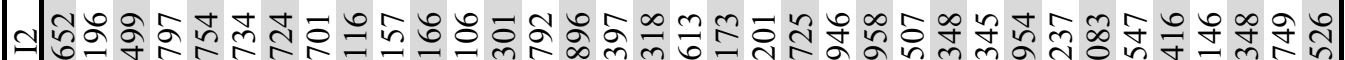
乙) 00000000000000000000000000000000000

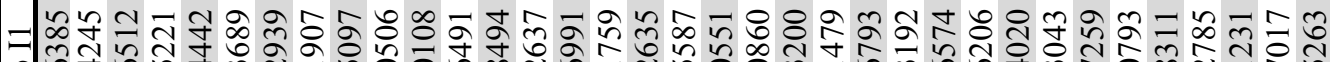

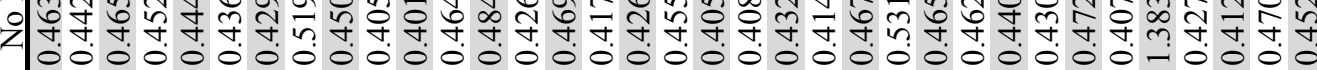

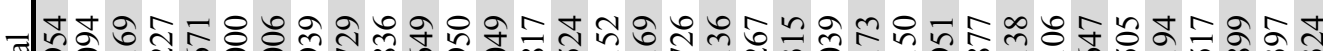
आ

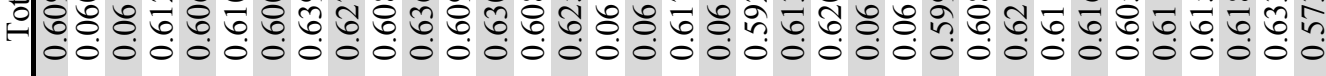
引ี 
Step 6: Sensitivity analysis is implemented by calculating the difference between the average of total efficiency score before and after elimination of each factor from the model. In this step the percentage of the impact of each factor on total efficiency score is calculated by the following equation:

$$
\text { percentage of the effect of factor(i) }=\frac{\mid \text { total efficiency }- \text { factor(i) efficiency } \mid}{\sum_{i=1}^{11} \mid \text { total efficiency }- \text { factor(i) efficiency } \mid} \times 100
$$

The calculated weight of factors from sensitivity analysis are presented in Fig. 3.

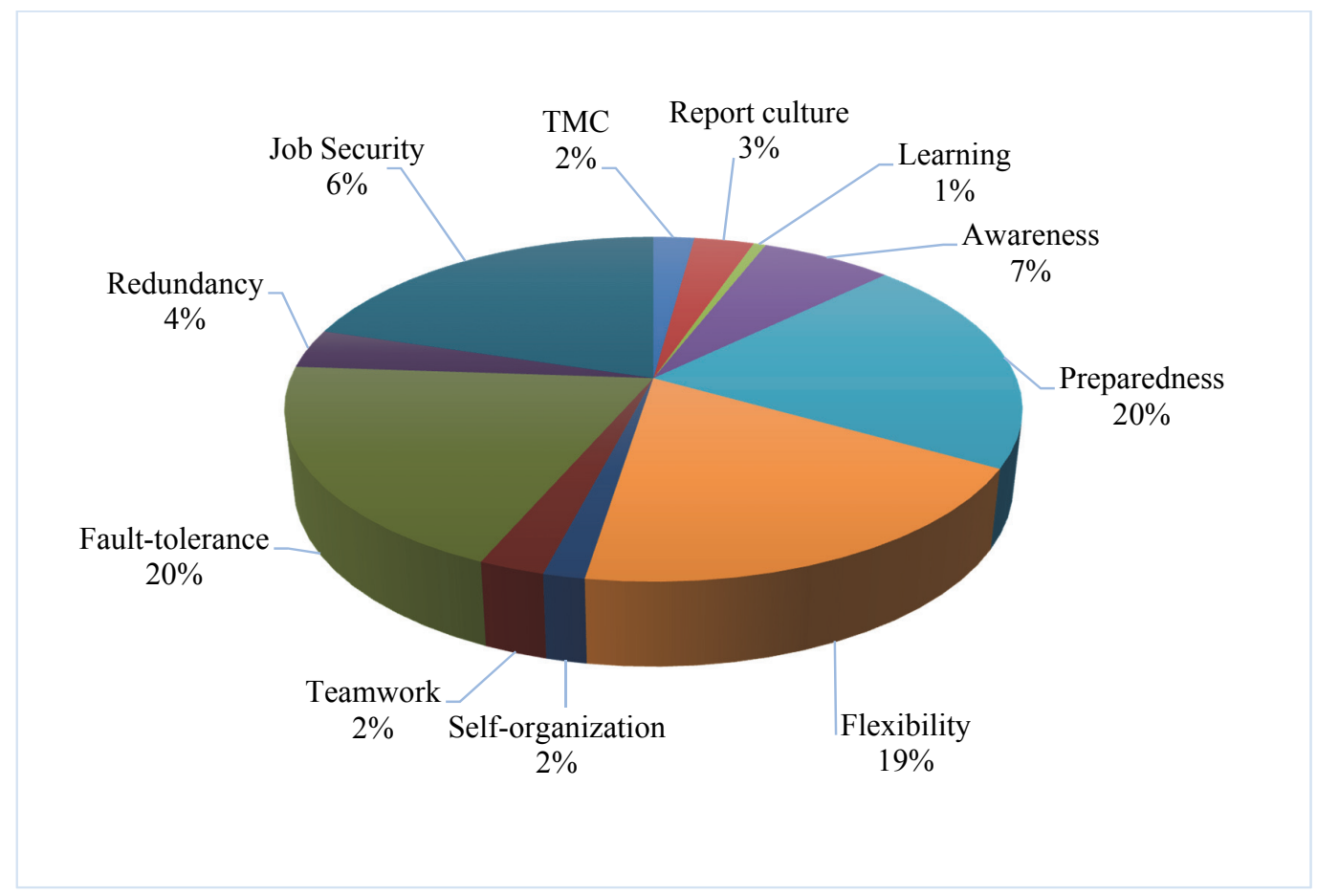

Fig. 3. The impact of each factor on total efficiency

The impact of overall resiliency versus job security is also demonstrated in Fig. 4.

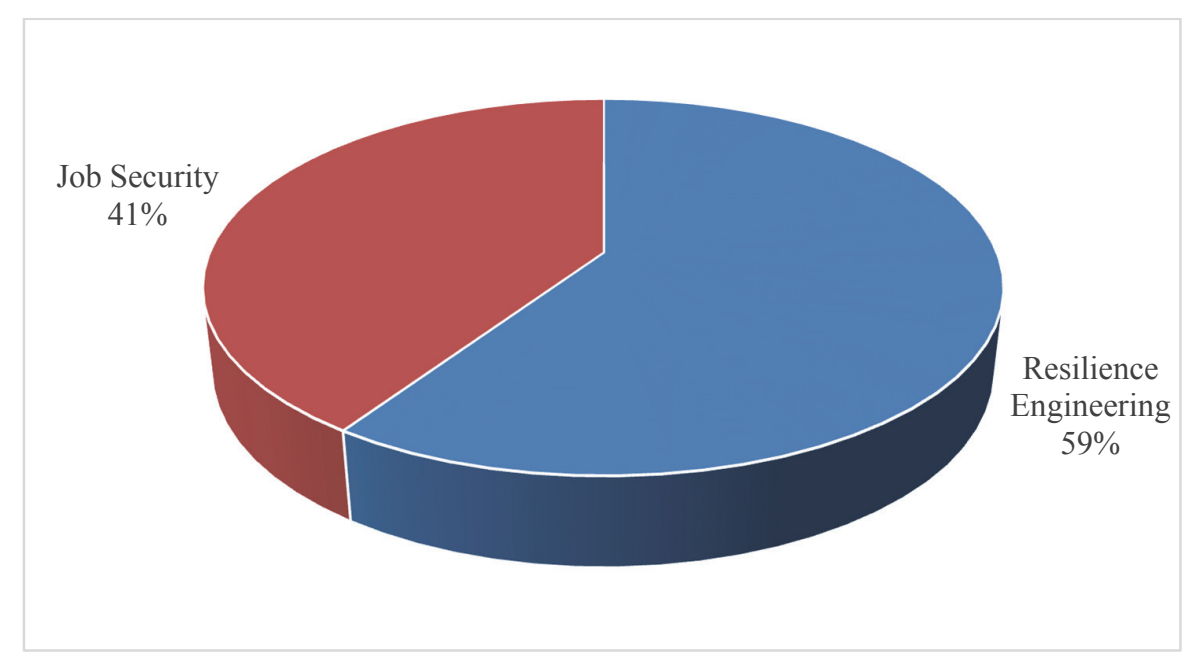

Fig. 4. The impact of overall resiliency versus job security 
In order to indicate the superiority of the proposed algorithm considering resilience engineering and job security concepts together, the efficiency scores of RE and job security factors are calculated separately, and the results are compared to the combined conceptual model of the presented study. The results are presented in Table 7.

Table 7

The superiority of the proposed integrated model versus separate concepts

\begin{tabular}{ccc}
\hline Factors & Average of Efficiencies & Comparison Result \\
\hline Combined RE and Job Security & $\mu_{\text {Combined }}=1.12764$ & - \\
Resilience Engineering & $\mu_{R E}=1.036452$ & $\mu_{\text {Combined }}>\mu_{R E}$ \\
Job Security & $\mu_{\text {Job Security }}=1.025467$ & $\mu_{\text {Combined }}>\mu_{\text {Job Security }}$ \\
\hline
\end{tabular}

\section{Conclusion}

Resilience engineering is a relatively new approach toward improving safety and performance critical systems. Also, job security is one of the work motivational factors that plays a significant role in the performance and efficiency of operators. Considering these concepts together can improve the performance and safety of the system significantly.

The efficiency of operators in project management area with respect to resilience engineering and job security was evaluated in this paper. For this purpose, an adaptive intelligent algorithm (ANN) was proposed which calculated the efficiency scores of all DMUs for each factor and determined the impact of factors on total efficiency. A construction site was selected as a case study and data were collected from 35 operators by distributing standard questionnaire.

The sensitivity analysis was performed and the weight of each factor on total efficiency was calculated. Results showed that five factors namely flexibility, fault-tolerance, preparedness, job security, and awareness have significant impact on the total efficiency of the project. The proposed algorithm is practical for large construction sites. It can be used for improvement of safety and performance by determining the weaknesses and strengths of the system. As a direction for future research, researchers can present an integrated model composed of motivational and resilience engineering factors along with economic indicators of the project, in order to improve both safety and economic performance of the project.

\section{References}

Azadeh, A., \& Ahranjani, P. M. (2014). The impact of job security, satisfaction and stress on performance assessment and optimization of generation companies. Journal of Loss Prevention in the Process Industries, 32, 343-348.

Azadeh, A., Rouzbahman, M., Saberi, M., \& Valianpour, F. (2014). An adaptive algorithm for assessment of operators with job security and HSEE indicators. Journal of Loss Prevention in the Process Industries, 31, 26-40.

Azadeh, A., Bonab, N. A., Salehi, V., \& Zarrin, M. (2015). A unique algorithm for the assessment and improvement of job satisfaction by resilience engineering: Hazardous labs. International Journal of Industrial Ergonomics, 49, 68-77.

Azadeh, A., \& Zarrin, M. (2016). An intelligent framework for productivity assessment and analysis of human resource from resilience engineering, motivational factors, HSE and ergonomics perspectives. Safety Science, 89, 55-71.

Azadeh, A., Foroozan, H., Ashjari, B., Motevali Haghighi, S., Yazdanparast, R., Saberi, M., \& Torki Nejad, M. (2017a). Performance assessment and optimisation of a large information system by combined customer relationship management and resilience engineering: a mathematical programming approach. Enterprise Information Systems, 11(9), 1401-1415. 
Azadeh, A., Yazdanparast, R., Zadeh, S. A., \& Zadeh, A. E. (2017b). Performance optimization of integrated resilience engineering and lean production principles. Expert Systems with Applications, 84, 155-170.

Blader, S. L., \& Tyler, T. R. (2009). Testing and extending the group engagement model: linkages between social identity, procedural justice, economic outcomes, and extrarole behavior. Journal of Applied Psychology, 94(2), 445.

Burtscher, M. J., \& Manser, T. (2012). Team mental models and their potential to improve teamwork and safety: a review and implications for future research in healthcare. Safety Science, 50(5), 13441354.

Cheng, G. H. L., \& Chan, D. K. S. (2008). Who suffers more from job insecurity? A meta-analytic review. Applied Psychology, 57(2), 272-303.

Costella, M. F., Saurin, T. A., \& de Macedo Guimarães, L. B. (2009). A method for assessing health and safety management systems from the resilience engineering perspective. Safety Science, 47(8), 1056-1067.

Cronbach, L. J. (1951). Coefficient alpha and the internal structure of tests. psychometrika, 16(3), 297334.

Dinh, L. T., Pasman, H., Gao, X., \& Mannan, M. S. (2012). Resilience engineering of industrial processes: principles and contributing factors. Journal of Loss Prevention in the Process Industries, $25(2), 233-241$.

Domínguez-García, A. D., Kassakian, J. G., Schindall, J. E., \& Zinchuk, J. J. (2008). An integrated methodology for the dynamic performance and reliability evaluation of fault-tolerant systems. Reliability Engineering \& System Safety, 93(11), 1628-1649.

Fewings, P. (2013). Construction project management: An integrated approach: Routledge.

Frangopol, D. M., \& Curley, J. P. (1987). Effects of damage and redundancy on structural reliability. Journal of Structural Engineering, 113(7), 1533-1549.

Loi, R., Ngo, H. Y., Zhang, L., \& Lau, V. P. (2011). The interaction between leader-member exchange and perceived job security in predicting employee altruism and work performance. Journal of Occupational and Organizational Psychology, 84(4), 669-685.

Ma, B., Liu, S., Liu, D., \& Wang, H. (2016). Job security and work performance in Chinese employees: The mediating role of organisational identification. International Journal of Psychology, 51(2), 123 129.

Morel, G., Amalberti, R., \& Chauvin, C. (2009). How good micro/macro ergonomics may improve resilience, but not necessarily safety. Safety science, 47(2), 285-294.

Plowman, D. A., Solansky, S., Beck, T. E., Baker, L., Kulkarni, M., \& Travis, D. V. (2007). The role of leadership in emergent, self-organization. The Leadership Quarterly, 18(4), 341-356.

Rasmussen, J., Pejtersen, A. M., \& Goodstein, L. P. (1994). Cognitive systems engineering.

Ray-Sannerud, B. N., Leyshon, S., \& Vallevik, V. B. (2015). Introducing Routine Measurement of Healthcare Worker's Well-being as a Leading Indicator for Proactive Safety Management Systems Based on Resilience Engineering. Procedia Manufacturing, 3, 319-326.

Reisel, W. D., Probst, T. M., Chia, S.-L., Maloles, C. M., \& König, C. J. (2010). The effects of job insecurity on job satisfaction, organizational citizenship behavior, deviant behavior, and negative emotions of employees. International Studies of Management \& Organization, 40(1), 74-91.

Sacks, R., Rozenfeld, O., \& Rosenfeld, Y. (2009). Spatial and temporal exposure to safety hazards in construction. Journal of construction engineering and management, 135(8), 726-736.

Saurin, T. A., \& Junior, G. C. C. (2012). A framework for identifying and analyzing sources of resilience and brittleness: a case study of two air taxi carriers. International Journal of Industrial Ergonomics, 42(3), 312-324.

Saurin, T. A., \& Júnior, G. C. C. (2011). Evaluation and improvement of a method for assessing HSMS from the resilience engineering perspective: A case study of an electricity distributor. Safety science, 49(2), 355-368. 
Shirali, G., Motamedzade, M., Mohammadfam, I., Ebrahimipour, V., \& Moghimbeigi, A. (2012). Challenges in building resilience engineering (RE) and adaptive capacity: A field study in a chemical plant. Process safety and environmental protection, 90(2), 83-90.

Siang, L. F., \& Yih, C. H. (2012). A comparative approach of Japanese project management in construction, manufacturing and IT industries. Procedia-Social and Behavioral Sciences, 57, 193 200.

Staufenbiel, T., \& König, C. J. (2010). A model for the effects of job insecurity on performance, turnover intention, and absenteeism. Journal of Occupational and Organizational Psychology, 83(1), 101-117.

Turner, M., \& Lingard, H. (2016). Improving workers' health in project-based work: job security considerations. International Journal of Managing Projects in Business, 9(3), 606-623.

Wehbe, F., Al Hattab, M., \& Hamzeh, F. (2016). Exploring associations between resilience and construction safety performance in safety networks. Safety Science, 82, 338-351.

Woods, D. D., \& Hollnagel, E. (2006). Prologue: resilience engineering concepts. Resilience engineering. Concepts and precepts, 1-16.

Wreathall, J. (2006). Properties of resilient organizations: an initial view Resilience engineering: Concepts and precepts (pp. 275-286): Ashgate, Aldershot, UK.

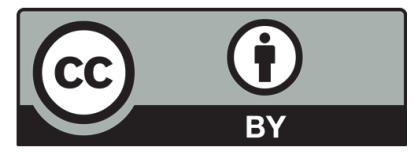

(C) 2017 by the authors; licensee Growing Science, Canada. This is an open access article distributed under the terms and conditions of the Creative Commons Attribution (CC-BY) license (http://creativecommons.org/licenses/by/4.0/).

\section{Appendix}

\section{Appendix 1}

The sample questions for each factor in the questionnaire

\begin{tabular}{|c|c|}
\hline Factor & Sample question \\
\hline TMC & Do you feel your boss appreciates your work? \\
\hline Report culture & $\begin{array}{l}\text { If personnel consult the boss -based on work experience- about the probability of sudden acci- } \\
\text { dent, will the boss pay attention to their view? }\end{array}$ \\
\hline Learning & $\begin{array}{c}\text { Do you think the feedback and review during accidents, as the report presented to the entire or- } \\
\text { ganization? }\end{array}$ \\
\hline Awareness & Do you ensure that you are aware of the safety issues related to your job? \\
\hline Preparedness & $\begin{array}{l}\text { Do you think the organization is prepared to deal with future incidents? (Establishment of an } \\
\text { emergency section and fire station in the workplace, ...) }\end{array}$ \\
\hline Flexibility & Are operators with multiple skills available for deployment in critical condition? \\
\hline Self-organization & $\begin{array}{l}\text { If sudden incidents happen, will you have the specific authority from the manager to make deci- } \\
\text { sions in an emergency situation? (Like stopping operation) }\end{array}$ \\
\hline Teamwork & $\begin{array}{c}\text { Do you think that operators are working together to correct mistakes for implementation of ap- } \\
\text { propriate programs? }\end{array}$ \\
\hline Fault-tolerance & $\begin{array}{l}\text { If required raw materials supply are less than normal state, will the company be able to continue } \\
\text { the project at an acceptable level? }\end{array}$ \\
\hline Redundancy & $\begin{array}{l}\text { If one of the supply centers of raw material or equipment faced with the trouble would there be } \\
\text { any alternative suppliers to avoid the work stop? }\end{array}$ \\
\hline Job security & Do you feel you have job security in the organization? \\
\hline
\end{tabular}




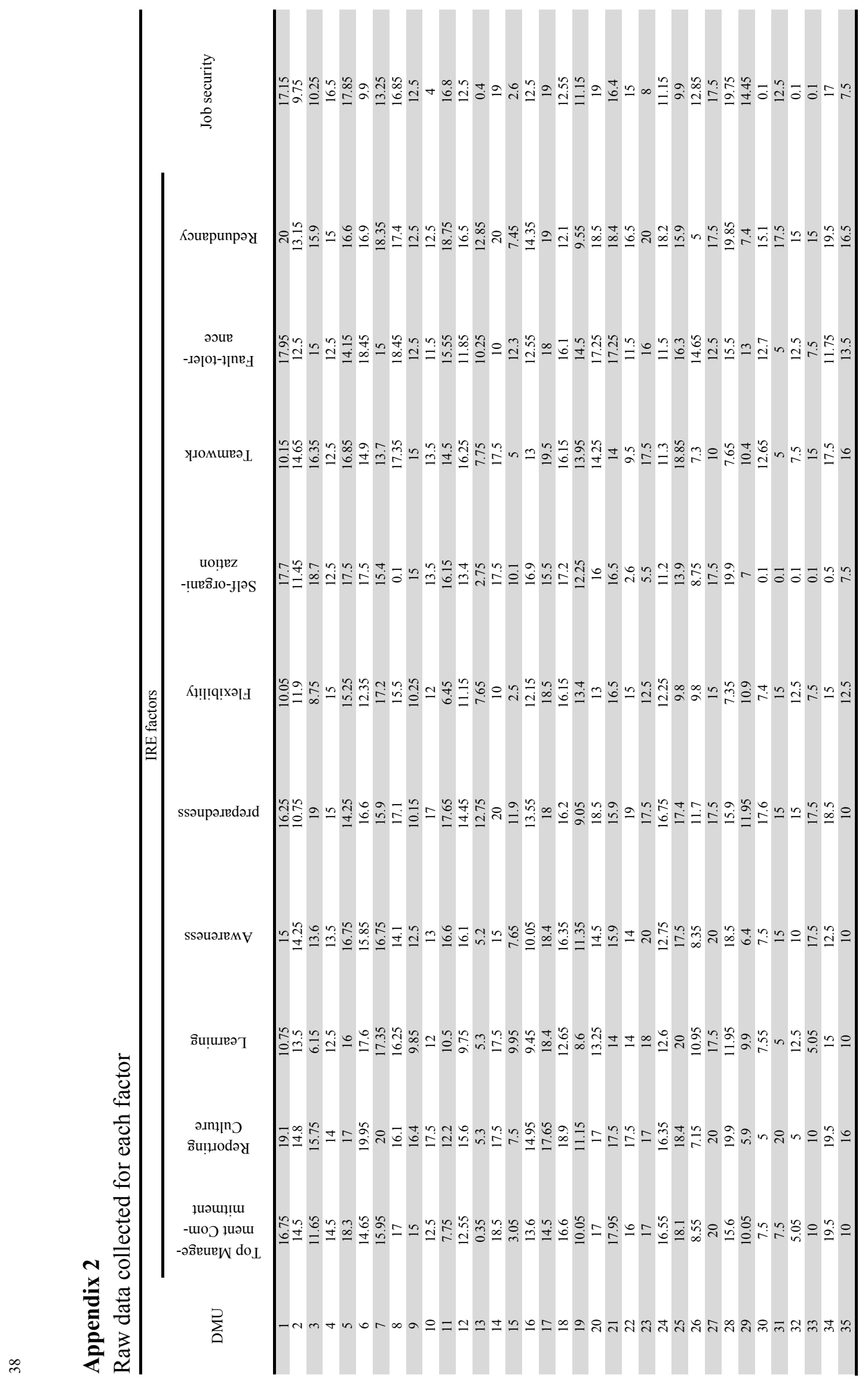

